\title{
Role of Unani (Greek) Therapy in the Treatment of Psoriasis- Case Series
}

\author{
Dr. Zamir Ahmad \\ Associate Professor, Department of Amraze Jild Wa Tazeeniyat (Unani Dermatology And Cosmetology), \\ A K Tibbiya College and Hospital, Aligarh Muslim University, Aligarh
}

\begin{abstract}
Psoriasis belongs to the group of skin diseases which have substantial burden with negative impact on quality of life of the patients due to unsatisfactory management and social isolation. This disease is mentioned in the vast classical Unani literature as Sadafia or Qashafia which means like the shell of Unio (freshwater mussels) or scaling respectively. Unani physicians are treating the patients of this disease successfully since centuries as per the described manner in the literature.

To validate the described Unani principles and management of Psoriasis in Unani (Greek) system of medicine, 09 patients were photographed before and after treatment for assessment of efficacy of the given Unani treatment on PASI scoring. All the patients responded well to this therapy with their entire satisfaction by achieving almost $100 \%$ cure clinically. Written informed consent was obtained from each patient for publication of their photographs for academic purpose.
\end{abstract}

Keywords: PASI scoring, Psoriasis, Unani (Greek) medicine, Unani principles

\section{Introduction}

Psoriasis is the commonest immune-mediated Papulosquamous skin disease ${ }^{1}$ manifested as a common, chronic, inflammatory scaly disorder having a substantial impact on quality of life $^{2}$ with the reported reduction in physical and mental functioning ${ }^{3}$. Prevalence rate $3.2 \%$ among adults in U.S. (estimated total of 7.2 million in 2010 and 7.4 million in 2013) ${ }^{4}$ is reported.

Globally various topical drugs, phototherapy and systemic medications are available for the treatment of Psoriasis with the variable outcome. In the year 2000, in United States, among the estimated4.55 million patients of Psoriasis, about 1.5 million reported their Psoriasis as a large problem of which 01 million were dissatisfied with its therapy. ${ }^{5}$ Survey of the National Psoriasis Foundation showed that the most accepted external treatment of Psoriasis is phototherapy with UV-B and methotrexate as an internal medication. Approximately 52.3\% patients of psoriasis and 45.5\% patients of Psoriasis with Psoriatic Arthritis were reported to be dissatisfied with their treatment. ${ }^{6}$

In absence of satisfactory cure of the Psoriasis, it is imperative to search better options in other traditional system of medicine. I found the mention of various descriptions of this disease in the various classical literature of Unani (Greek) Medicine in different languages, mainly in Arabic, Persian and Urdu. I decided to validate by documenting the outcome of the Unani (Greek) treatment.

Treatment was initiated according to Principles of Unani (Greek) Medicine with the oral drugs aiming to normalize the humours of the patients by means of Unani drugs having required actions of purification (alleviation of acrid materials) of blood, relieving (normalization of hyper functioning) of skin cells along with correctives for immune functioning of the body.

The drug for local application was prepared by adding the Unani drugs having required actions; keratolylic, relieving, anti-inflammatory and anti-microbial along with moisterization.

\section{Case Series}

In this series, total 09 patients with mild to severe Psoriasis were treated in the Department of Amraze jild wa tazeeniyat (Unani Dermatology \& Cosmetology), AK Tibbiya college and Hospital, Aligarh Muslim University, Aligarh, U.P., India. These patients were having characteristic Silvery scales on various parts of their bodies; scalp, chest, abdomen, back, upper extremities, lower extremities.

All patients were previously diagnosed and treated by the physicians of various system of medicines; Allopathy, Ayurveda and Homeopathy with dissatisfaction in improvement in their psoriasis. They were photographed for prior and post treatment condition of the lesions and assessed on the PASI scoring.

These patients received following Unani drugs orally-

1- Syrup containing following ingredients in equal ratio, $10 \mathrm{ml}$ twice a day.

a. Khus (Vetiveria zizanoides)- Grass

b. Ward (Rosa damascena mill.) - Petals of flowers

c. Sandal safaid (Santalum album) - Fine powder of wood

DOI: 10.9790/0853-1509122427 www.iosrjournals.org 
d. Sandal Surkh (Pterocarphs santalinus ) - Fine powder of wood

e. Unnab ( Zizyphus jujuba Linn.) - Fruit

f. Ersa (Iris ensata Thunb ) - Leaves

2- Tablet, 'Qurse Kafoor' containing following ingredients in equal ratio - 01 tablet twice daily.

a. Tukhme kahu (Lactuca sativa Linn.) - Seed

b. Tukhme khurfa (Portulaea oleracea Linn.)- Seed

c. Tabasheer (Bambusa bambos Druce.)- Secretion of plant

d. Rubus Soos (Glycyrrhizia glabra Linn.) - Root

e. Ward (Rosa damascena mill.) - Petals of flowers,

f. Kishneez khushak (Coriandrum sativum Linn.) - Seed

g. Aqaqiya (Acacia arabica Willd)- Gum

h. Gile armani (Armenian Bole) - Mineral

i. Gulnar (Punica granatum linn.) Fruit

j. Burada Sandal Safaid (Santalum album)- Fine powder of wood

k. Kafoor (Cinnamomum camphora Nees )- Camphor

3- Oil of Badaam Sheerin (Prunus amygdalus) seed- 05drops mixed with milk once daily

4- Externally, a paste of Unani drugs containing following ingredients, was used and applied on the lesions upto the vanishing of lesions clinically.

a. Kibreet (Sulphur) - Mineral

b. Suhaga (Borex) - Mineral

c. Kafoor(Cinnamomum camphora Nees)- Camphor

d. Roghan kunjad (Sesamum indicum Linn.)- Oil as a base

\section{Observation and Results}

Among the total 09 patients between 13 to 60 years of age, 05 were females and 04 males with 2.0 lowest PASI scoring and 37.8 the maximum before starting the Unani treatment.

After the treatment 08 patients were completely cure with 0.0 PASI scoring and remaining one patient was almost cured with 0.4 PASI scoring.

Two patients cured within 18 days only, which was the shortest duration of this treatment on record and the longest duration of treatment was documented as 9 months 15 days in these patients.

The patients experienced marked improvement in their psoriasis within few days after the start of this treatment. Itching was relived within days. Scaling was reduced and areas of normal skin started emerging within few days to weeks. After few months, psoriasis was almost $100 \%$ cured without any side effect.

\section{Conclusions}

Unani drugs significantly improved Psoriasis clinically with the almost $100 \%$ improvement in PASI scoring. Excellent tolerance and acceptability were also observed among these patients without any reported side effect.

\section{Future Vision of Treatment of Psoriasis}

Randomized clinical trials are needed to reveal whether Unani medicine can provide a new and novel therapeutic option for satisfactory treatment of Psoriasis.

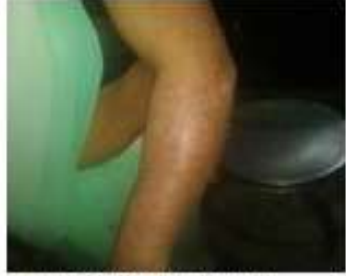

1at-before treatment

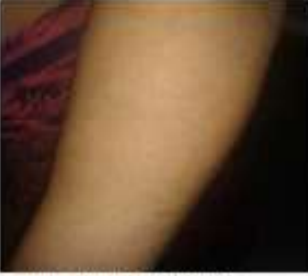

1ay-after treatment

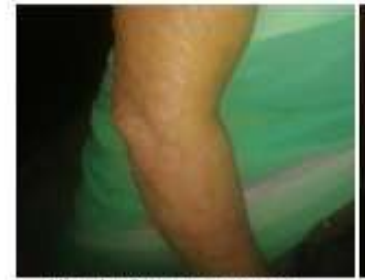

1bi-before treatment

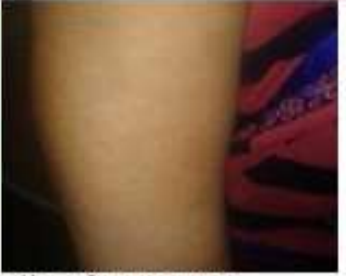

1ba- after treatment 
Role Of Unani (Greek) Therapy In The Treatment Of Psoriasis- Case Series

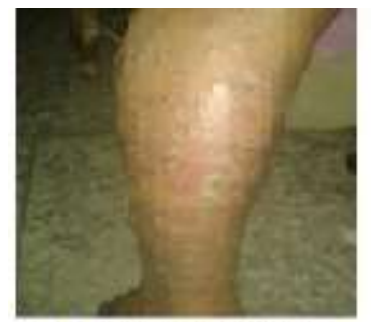

1c1-before treatment

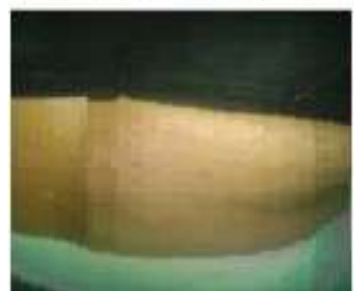

1e1-before treatment

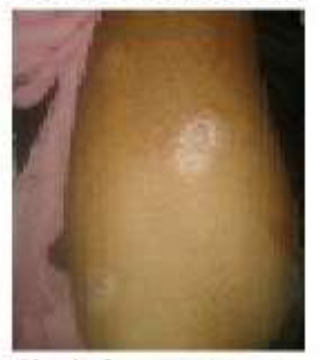

$2 b_{1}$-before treatment

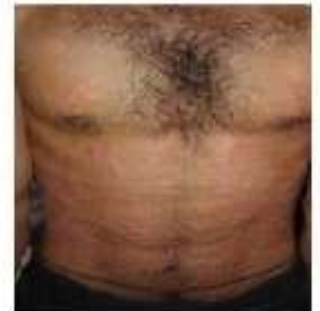

Bas-before treatment
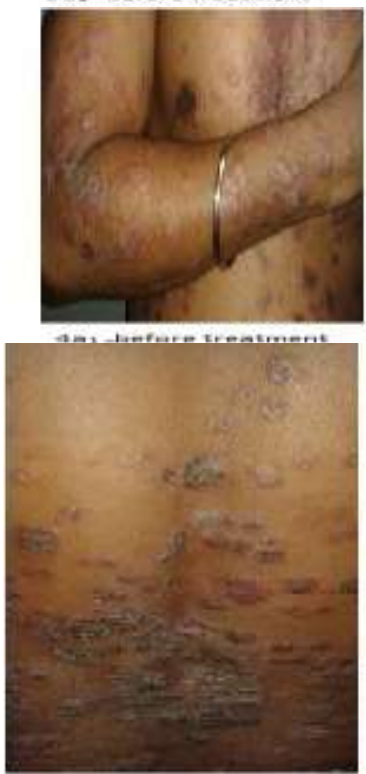

$4 c_{1}$ befare treatment

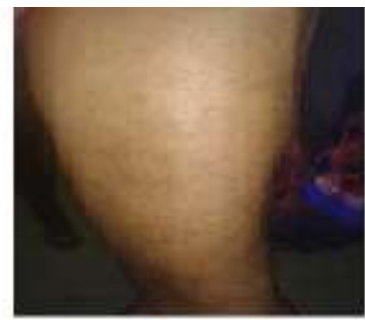

1e2-after treatment

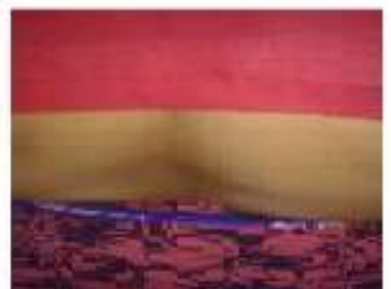

1e2-after treatment
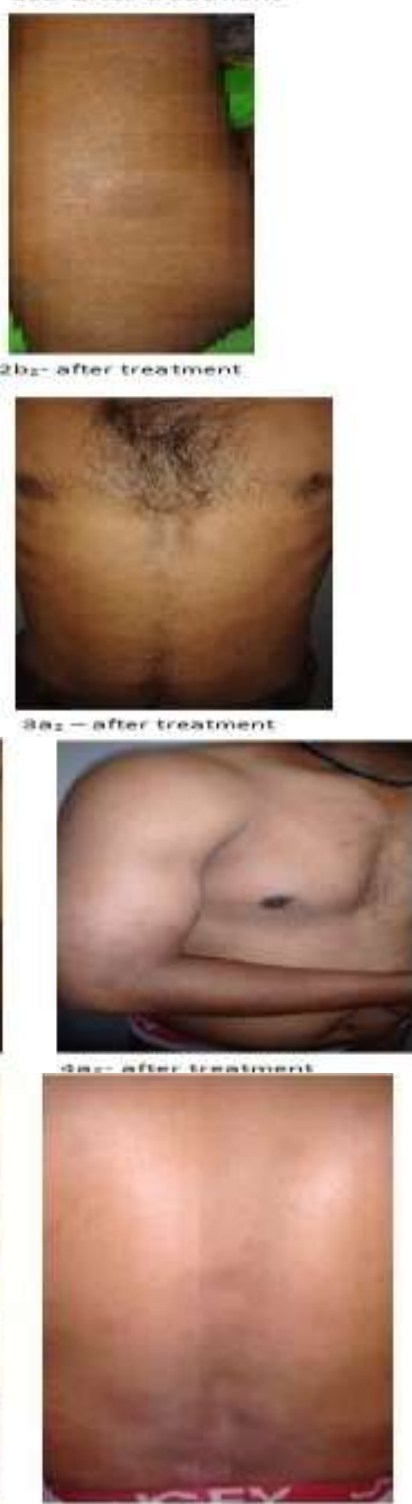

4c2-nfter tremtment

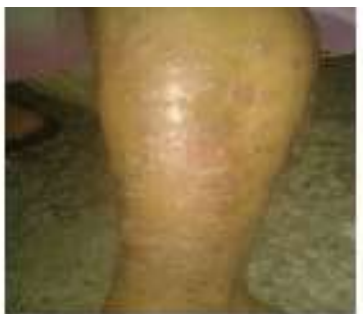

1d1-before treatment

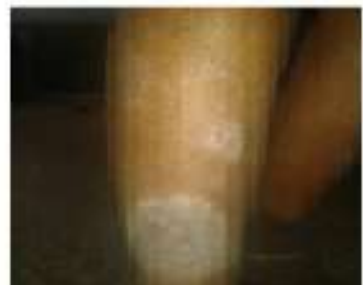

2a1-before treatment

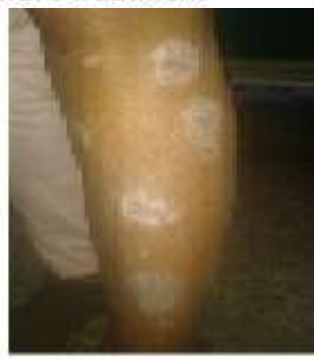

$2 c_{1}$-before treatmen

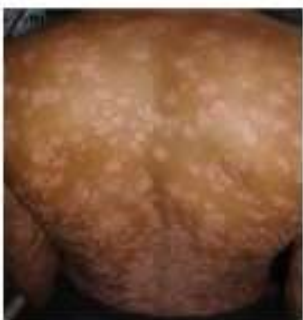

Abi-before treatmen
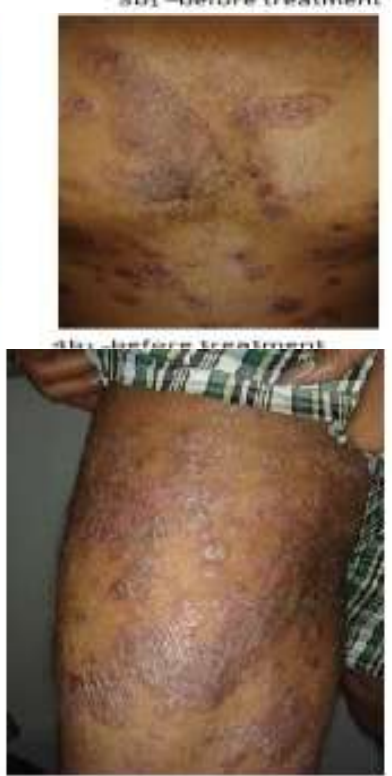

4di before treatment

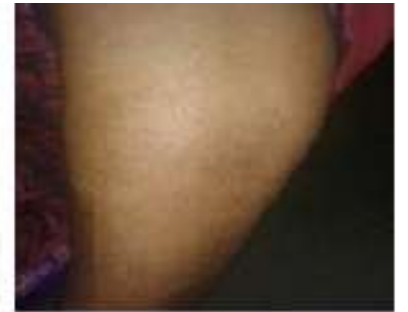

1d2-after treatment

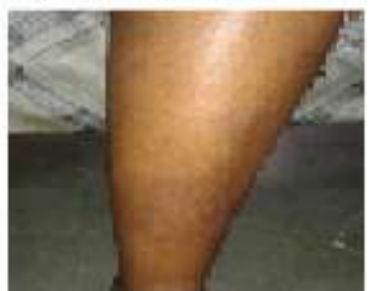

2az-after treatment

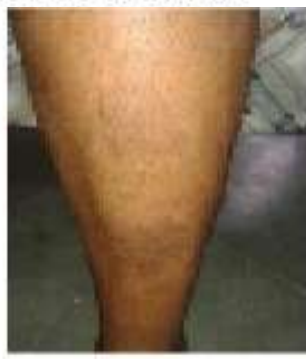

$26 x$-ofter treatment

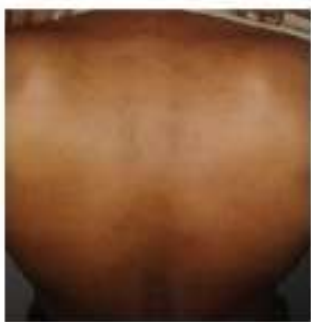

$3 b=$-after treatmert
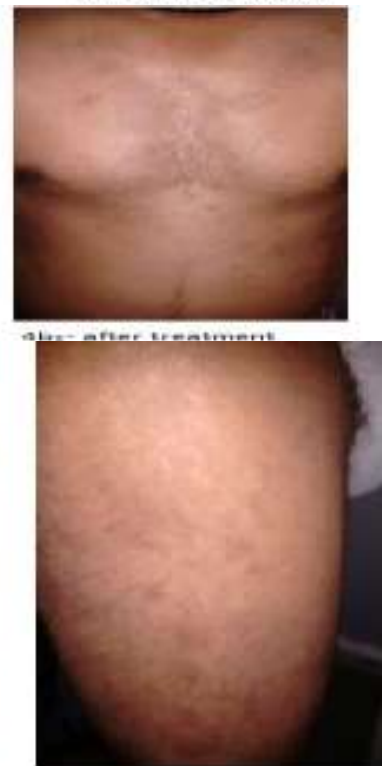

$4 d_{2}$ - wfter treatment 


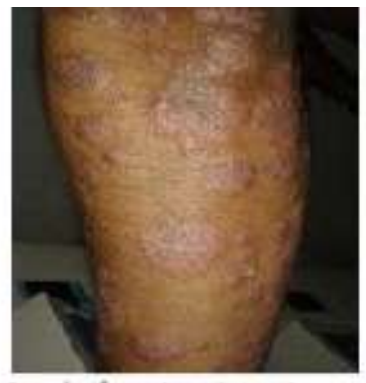

$4 e_{1}$-before treatment

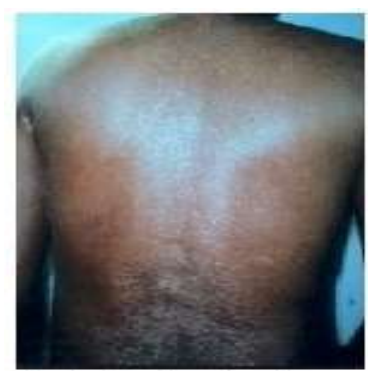

$5 b_{1}$-before treatment

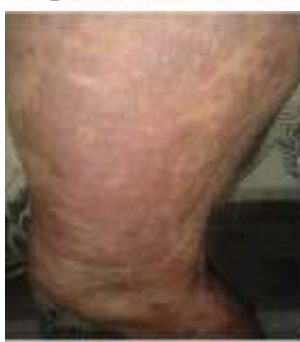

sas-before trentment

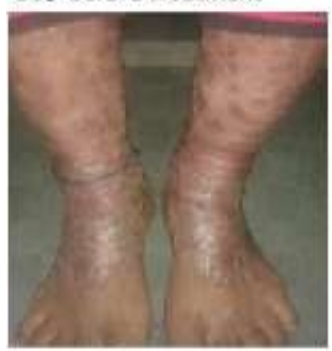

7as thefare treatment

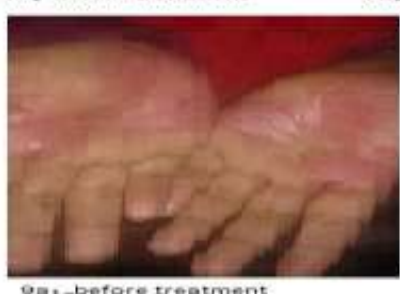

Oan betore treatment

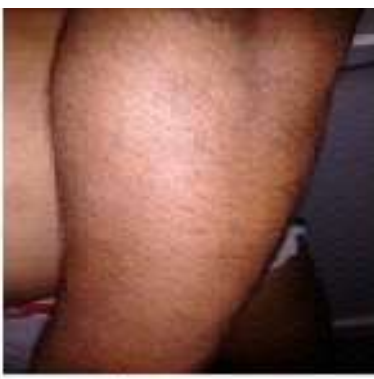

4ez- after treatment

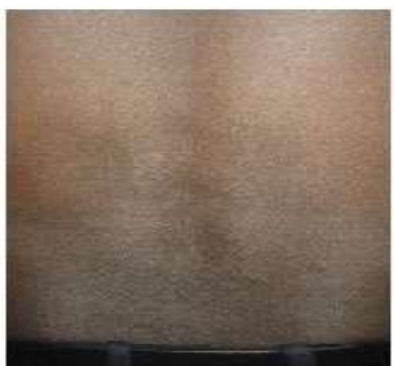

5b2-after treatment

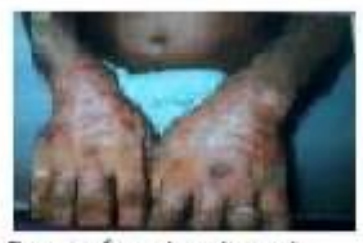

Sal uefore treatment

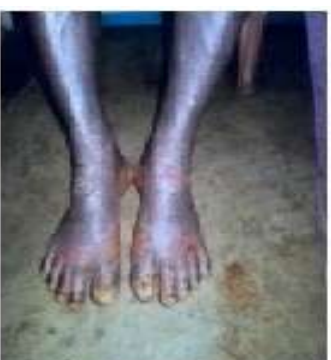

$5 c_{1}$-before treatment

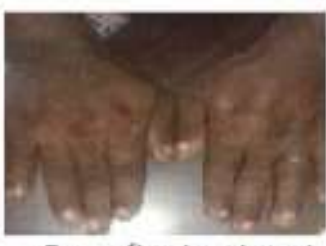

Saz-after treatment

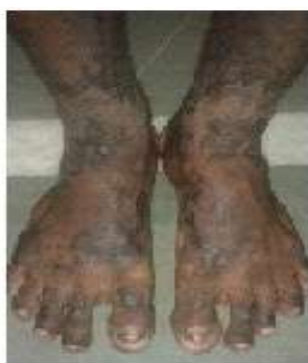

5c2-after treatment
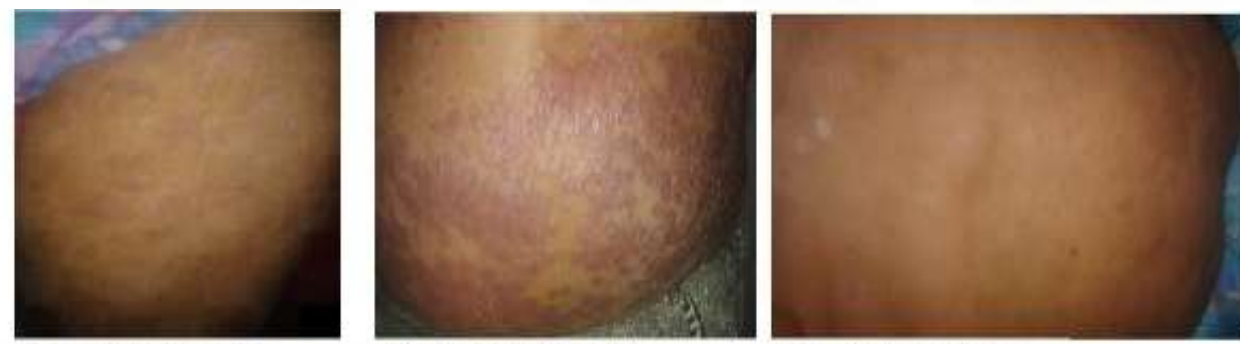

Sarateretrentment

Shi heftere trentment

shav after treatmerit
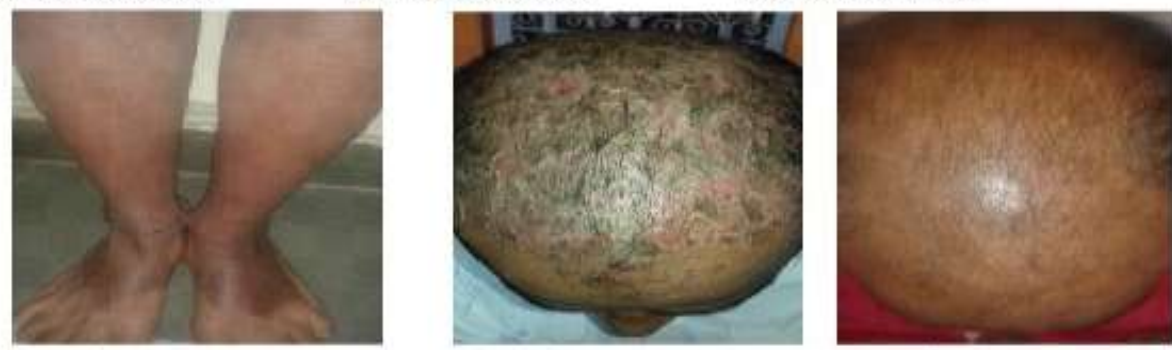

gas theftare vatment

mav- after weatment

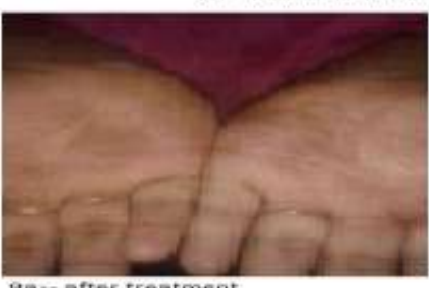

References

[1]. Christopher EM Griffiths and Jonathan NWN Barker, M "Pathogenesis and clinical features of psoriasis" The Lancet, Volume 370, Issue 9583, 21-27 July 2007, Pages 263-271

[2]. Joel M. Gelfand, Rachel Weinstein, Steven B. Porter, Andrea L. Neimann, Jesse A. Berlin, David J. Margolis, "Prevalence and Treatment of Psoriasis in the United Kingdom: A Population-Based Study "JAMA Dermatology, December 1, 2005 , Vol 141, No. 12

[3]. Stephen R. Rapp, Steven R. Feldman, M.LynExum, Alan B. Fleischer Jr, David M. and Reboussin, "Psoriasis causes as much disability as other major medical diseases", Journal of the American Academy of Dermatology, Volume 41, Issue 3, September 1999, Pages 401-407

[4]. Tara D. Rachakonda, Clayton W. Schupp and April W. Armstrong, "Psoriasis prevalence among adults in the United States", Journal of the American Academy of Dermatology, Volume 70, Issue 3, March 2014, Pages 512-516

[5]. Robert S. Stern, Tamar Nijsten, Steven R. Feldman, David J. Margolis and Tara Rolstad, "Psoriasis Is Common, Carries a Substantial Burden Even When Not Extensive, and Is Associated with Widespread Treatment Dissatisfaction" Journal of Investigative Dermatology Symposium Proceedings, Volume 9, Issue 2, March 2004, Pages 136-139

[6]. April W. Armstrong, Andrew D. Robertson, Julie Wu, Clayton Schupp and Mark G. Lebwohl, "Undertreatment, Treatment Trends, and Treatment Dissatisfaction Among Patients With Psoriasis and Psoriatic Arthritis in the United States Findings From the National Psoriasis Foundation Surveys, 2003-2011”JAMA Dermatology, October 2013;149(10):1180-1185 